\title{
Sugar-oxidizing Respiratory Chain of Gluconobacter suboxydans. Evidence for a Branched Respiratory Chain and Characterization of Respiratory Chain-Linked Cytochromes
}

\author{
Minoru Ameyama, Kazunobu Matsushita, Emiko Shinagawa \\ and Osao ADACHI
}

Department of Agricultural Chemistry, Faculty of Agriculture, Yamaguchi University, Yamaguchi 753, Japan

Received May 15, 1987

\begin{abstract}
Gluconobacter suboxydans has a highly active respiratory chain which oxidizes several sugars and sugar alcohols. The results of this study indicate that the sugar-oxidizing respiratory chain consists of ubiquinone, several cytochromes $c$ and a cytochrome $o$. The respiratory chain was shown to contain at least five cytochromes, including two cytochromes $c$ associated with alcohol or aldehyde dehydrogenase, two cytochromes $c$ that react with carbon monoxide and a single cytochrome $o$, some of which were characterized in this study. Furthermore, several lines of evidence suggest that the respiratory chain branchs at the site of ubiquinone with $\mathrm{KCN}$-sensitive and -insensitive terminal oxidases, which may correspond to cytochrome $o$ oxidase and an alternative oxidase consisting of a possible cytochrome $c$, respectively.
\end{abstract}

Gluconobacter strains are well known to be oxidative bacteria which not only oxidize ethanol to acetic acid and D-glucose to D-gluconic acid, but which are also ketogenic on sugars such as D-gluconic acid, D-sorbitol, glycerol and so on. ${ }^{1)}$ These sugar oxidation reactions are mediated by an electron transport system located in the cytoplasmic membrane of the organisms. $\left.{ }^{2}\right)$

The results of earlier analysis on the electron transport system of Gluconobacter suboxydans suggested that the organism contained cytochromes $c, b$ and $o .{ }^{3,4)}$ Daniel $^{5)}$ has conducted more detailed analysis and has clearly shown that the respiratory chain contains only cytochromes $c$ and $o$ but no cytochrome $b, d$ or $a$. He also suggested that the electron transport system consisted of ubiquinone, tow kinds of $c$-type cytochrome and two kinds of $b$-type cytochrome which correspond to two cytochromes $o$ functioning as terminal oxidases.

We have so far solubilized, purified and characterized a wide variety of primary dehydrogenases involved in sugar oxidation. ${ }^{6 \sim 12)}$
During these studies, several cytochromes $c$ associated with or without dehydrogenases were isolated. Purified alcohol and aldehyde dehydrogenases were accompanied by cytochrome $c-553[c-553(\mathrm{AD})]^{6)}$ and cytochrome $c-551[c-551(\mathrm{AL})]{ }^{7)}$ respectively, while $\mathrm{CO}$ reactive cytochrome $c-553[c-553(\mathrm{CO})]$ was purified as a single component. ${ }^{13)}$

In this communication, we report the characterization of the cytochromes solubilized and purified from $G$. suboxydans membranes, including cytochrome $c$-553 (AD), cytochrome $c$-551 (AL) and newly isolated CO-reactive cytochrome $c-551$ [ $c-551(\mathrm{CO})]$. We also report that the respiratory chain of the organism may be branched, with cytochrome $o$ and an alternative terminal oxidase that may contain some cytochrome $c$.

\section{MATERIALS AND METHODS}

Bacterial strain and growth conditions. G. suboxydans IFO 12528 was used throughout this work. The growth medium (sugar-rich medium) consisted of $20 \mathrm{~g}$ of sodium D-gluconate, $5 \mathrm{~g}$ of D-glucose, $3 \mathrm{~g}$ of glycerol, $3 \mathrm{~g}$ of yeast 
extract and $2 \mathrm{~g}$ of polypeptone in 1-1 of tap water. Cultivation was performed aerobically with rotary shaking or in a $50-1$ jar fermentor at $30^{\circ} \mathrm{C}$.

Preparation of membranes. Cells were harvested by centrifugation and then washed twice with distilled water. The cell paste was suspended in $10 \mathrm{~mm}$ potassium phosphate buffer (KPB), pH 6.0, and then passed through a French pressure cell press at 16,000 psi. After centrifugation at $10,000 \times g$ for $10 \mathrm{~min}$ to remove intact cells, the supernatant was centrifuged at $68,000 \times g$ for $1 \mathrm{hr}$. The resultant precipitate was washed once with $10 \mathrm{~mm}$ KPB (pH 6.0).

Solubilization and fractionation of cytochromes from the membranes. Membranes were suspended in $10 \mathrm{~mm}$ sodium acetate buffer ( $\mathrm{pH} 5.0$ ), to a final protein concentration of about $10 \mathrm{mg} / \mathrm{ml}$. Brij 58 and Tween 80 were added to the membrane suspension to concentrations of 2 and $1 \%$, respectively, followed by stirring for $2 \mathrm{hr}$ on ice. The suspension was centrifuged at $68,000 \times g$ for $1 \mathrm{hr}$ to obtain "supernatant I." The precipitate was resuspended


$\mathrm{X}-100$ was added to a concentration of $1 \%$, the final protein concentration being about $10 \mathrm{mg} / \mathrm{ml}$. After stirring for $2 \mathrm{hr}$, the suspension was centrifuged as above and "supernatant II" was obtained. The resultant precipitate was suspended in $10 \mathrm{~mm} \mathrm{KPB} \mathrm{(pH} \mathrm{7.0),} \mathrm{and}$ then Triton $\mathrm{X}-100$ and $\mathrm{KCl}$ were added to the suspension to concentrations of $2 \%$ and $1 \mathrm{M}$, respectively. The suspension was stirred overnight on ice and then centrifuged to obtain "supernatant III."

Partial purification of cytochrome c-551 (CO) and cytochrome $o$. Supernatant III, obtained as described above, was mixed with $3 \%$ sodium cholate, and then ammonium sulfate was added to the mixture to a concentration of $20 \%$. After stirring on ice for $10 \mathrm{~min}$, the mixture was centrifuged at $10,000 \times g$ for $10 \mathrm{~min}$. To the resultant supernatant, ammonium sulfate was added to $40 \%$, followed by stirring for $10 \mathrm{~min}$ on ice. The precipitate obtained on centrifugation was suspended in $10 \mathrm{~mm}$ sodium acetate buffer ( $\mathrm{pH} 5.0$ ) containing $0.5 \%$ Triton $\mathrm{X}$ 100 , and then the suspension was dialyzed against the same buffer overnight. The dialysate was applied to a DEAE-cellulose column $(2.5 \times 15 \mathrm{~cm})$ which had been equilibrated with $10 \mathrm{~mm}$ sodium acetate buffer $(\mathrm{pH}$ 5.0) containing $0.5 \%$ Triton $\mathrm{X}-100$. Cytochrome $c-551$ (CO) was eluted in the pass-through fraction, and then cytochrome $o$ was eluted with the same buffer containing $0.5 \mathrm{M} \mathrm{KCl}$. Both fractions were concentrated by ultrafiltration and then used as the partially purified samples.

Analytical procedures. Hemes $b$ and $c$, and cytochrome $o$ contents were determined as described. ${ }^{14)} \mathrm{CO}$-Binding cytochrome was determined, as in the case of cytochrome $o$ except for the addition of $0.2 \%$ deoxycholate to the assay mixture. Cytochrome $c$ content was determined from the reduced minus oxidized difference spectrum using a millimolar extinction coefficient of 19 .

Oxidase activities for NADH, glucose, ethanol and glycerol were measured polarographically with a Clarktype oxygen electrode at $25^{\circ} \mathrm{C}$. The reaction mixture contained $50 \mathrm{~mm}$ KPB (pH 6.5), $1 \mathrm{~mm} \mathrm{NADH}$ or $10 \mathrm{~mm}$ another substrate, and membranes in a total volume of $3 \mathrm{ml}$. Reduced ubiquinone- $1\left(\mathrm{Q}_{1} \mathrm{H}_{2}\right)$ oxidase activity was measured spectrophotometrically by following the decrease in absorbance at $275 \mathrm{~nm}$. The reaction mixture contained $50 \mathrm{mM}$ KPB (pH 6.5), $80 \mu \mathrm{M} \quad \mathrm{Q}_{1} \mathrm{H}_{2}$ and membranes.

Reduction level of ubiquinone was measured as described previously. ${ }^{14)}$ Kinetic analysis of cytochromes was performed with a dual wavelength spectrophotometer as described. ${ }^{14)}$ The wavelength pairs used were $552 \sim 540 \mathrm{~nm}$ for cytochrome $c$ and $565 \sim 575 \mathrm{~nm}$ for cytochrome $o$.

Midpoint redox potential was determined by two different methods using iron-EDTA ${ }^{15)}$ and iron-oxalate ${ }^{16)}$ systems. The reductive titration of cytochrome with the iron-EDTA system $\left(E_{0}=+117 \mathrm{mV}\right)$ was carried out anaerobically in a Thunberg-type cuvette by adding $10 \mathrm{~mm}$ ferrous ammonium sulfate to a solution containing cytochrome, $10 \mathrm{~mm}$ EDTA, $0.5 \mathrm{~mm}$ ferric ammonium sulfate and $100 \mathrm{~mm}$ Tris-acetate buffer $(\mathrm{pH} 7.0)$. Alternative measurement with the iron-oxalate system $\left(E_{0}=+2 \mathrm{mV}\right)$ was performed, as in the case of the iron-EDTA system, in a reaction mixture containing cytochrome, $100 \mathrm{~mm}$ potassium oxalate, $0.5 \mathrm{~mm}$ ferric ammonium sulfate and $100 \mathrm{~mm}$ Tris-acetate buffer (pH 7.0).

Other analytical procedures. Protein content was determined as described. ${ }^{17)}$ Low temperature-absorption spectrum was taken in liquid nitrogen in a cuvette of $2 \mathrm{~mm}$ light path. Sodium dodecyl sulfate (SDS)-polyacrylamide gel electrophoresis and heme-staining were performed as described. ${ }^{18)}$

Materials. Cytochromes $c-553$ (AD) and $c-551$ (AL) were prepared as described previously. ${ }^{6,7)} \mathrm{Q}_{1}$ was kindly supplied by Eizai Co. and Nissin-Seifun Co. $\mathrm{Q}_{1} \mathrm{H}_{2}$ was prepared from $Q_{1}$ as described by Rieske. ${ }^{19)}$ 2-Heptyl-4hydroxyquinoline $\mathrm{N}$-oxide (HQNO) was obtained from Sigma. All other chemicals were of reagent grade and obtained from commercial sources.

\section{RESULTS}

\section{Respiratory components in membranes of $G$. suboxydans}

The membranes of G. suboxydans exhibit high sugar-oxidizing activity as well as NADH oxidase activity. Table I shows the NADH, glucose, ethanol and glycerol oxidase activities 
in the membranes, and also the sensitivity to $\mathrm{KCN}$ or HQNO of each oxidase system. All these systems are relatively resistant to these respiratory inhibitors, except for NADH oxidase which shows lower resistance to HQNO.

Daniel $^{5)}$ has already determined the content of cytochromes $c$ and $o$, flavoprotein and ubiquinone in the membranes of G. suboxydans grown with glycerol as a carbon source. In this study, the content of the respiratory components were examined in membranes of

Table I. Oxidase Activities in Membranes OF G. suboxydans AND EFFECT OF

RESPIRATORY INHIBITORS

\begin{tabular}{lccc}
\hline & & \multicolumn{2}{c}{ Inhibition $(\%)$} \\
\cline { 3 - 4 } Substrates & $\begin{array}{c}\text { Oxidase activity } \\
(\mu \text { atom O/min/mg) }\end{array}$ & $\begin{array}{c}\text { With 1 mM } \\
\text { KCN }\end{array}$ & $\begin{array}{c}3 \mu \mathrm{M} \\
\text { HQNO }\end{array}$ \\
& & 24 & 85 \\
NADH & 2.22 & 42 & 28 \\
Glucose & 1.14 & 44 & 48 \\
Ethanol & 1.64 & 39 & 57 \\
Glycerol & 1.56 & & \\
\hline
\end{tabular}

Table II. CONTENT OF Respiratory Components in Membranes of G. suboxydanis

\begin{tabular}{lc}
\hline Components & $\begin{array}{c}\text { Content } \\
\text { (nmol/mg protein) }\end{array}$ \\
\hline Heme $c$ & 1.35 \\
Heme $b$ & 0.36 \\
Cytochrome $c$ & 1.30 \\
Cytochrome $o$ & 0.31 \\
CO-Binding cytochrome & 0.61 \\
\hline
\end{tabular}

the organism grown in sugar-rich medium that contained D-glucose, D-gluconate and glycerol as carbon sources (Table II). Of the respiratory components examined, only the content of cytochrome $c$ was significantly higher in the membranes of cells grown in sugar-rich medium compared with that in glycerol medium reported by Daniel. ${ }^{5)}$

\section{Reduction kinetics of the respiratory com- ponents}

Kinetic experiments on the respiratory components in the NADH oxidase system have already been performed by Daniel. ${ }^{5)}$ The same kinds of the experiments were carried out on the sugar-oxidizing respiratory system of $G$. suboxydans grown in sugar-rich medium. As can be seen in Table III, the results clearly indicate that ubiquinone, and cytochromes $c$ and $o$ are all involved in the sugar-oxidizing respiratory chain as well as the NADH oxidase system. Furthermore, the reduction level of each respiratory component in the aerobic steady state suggests that ubiquinone is located close to primary dehydrogenases, and cytochrome $o$ near the terminal end. The reduction level of $c$-type cytochrome in the aerobic steady state lies between those of ubiquinone and cytochrome $o$, but it is not much enhanced by $\mathrm{KCN}$ or $\mathrm{HQNO}$, though $\mathrm{KCN}$ increases that of cytochrome $o$ (Table IV). Furthermore, as shown in Fig. 1, reduction of $c$-type cytochrome with glucose, ethanol or glycerol occurs gradually after the reaction system has

Table III. Reduction LeVels of Respiratory Components in Membranes of G. suboxydans in the Aerobic Steady State and the Anaerobic State

\begin{tabular}{|c|c|c|c|c|c|c|}
\hline \multirow{3}{*}{$\begin{array}{c}\text { Respiratory } \\
\text { substrates }\end{array}$} & \multicolumn{6}{|c|}{ Reduction level ( $\%)$} \\
\hline & \multicolumn{2}{|c|}{ Ubiquinone } & \multicolumn{2}{|c|}{ Cytochrome $c$} & \multicolumn{2}{|c|}{ Cytochrome $o$} \\
\hline & Aerobic & Anaerobic & Aerobic & Anaerobic & Aerobic & Anaerobic \\
\hline $\mathrm{NADH}$ & $60 \pm 9$ & $81 \pm 8$ & $37 \pm 4$ & $93 \pm 3$ & $5 \pm 5$ & $91 \pm 5$ \\
\hline Glucose & $65 \pm 4$ & $89 \pm 5$ & $25 \pm 3$ & $71 \pm 2$ & $7 \pm 8$ & $87 \pm 5$ \\
\hline Ethanol & $43 \pm 8$ & $70 \pm 8$ & $37 \pm 6$ & $74 \pm 7$ & $4 \pm 4$ & $96 \pm 4$ \\
\hline Glycerol & $41 \pm 5$ & $65 \pm 3$ & $22 \pm 3$ & $72 \pm 5$ & $0 \pm 0$ & $76 \pm 6$ \\
\hline
\end{tabular}

The reduction level of each component was determined as described under MATERIALS AND METHODS. The values are the mean values and standard deviations for $6 \sim 10$ separate experiments. 
TABle IV. EFFeCt OF Respiratory InHIBITORS ON THE ReDUCtion LEVELS OF Cytochrome $c$ AND Cytochrome o IN Membranes of G. suboxydans

The experiments were carried out as described under MATERIALS AND METHODS with or without $1 \mathrm{~mm}$ $\mathrm{KCN}$ or $3 \mu \mathrm{M}$ HQNO.

\begin{tabular}{|c|c|c|c|c|c|c|c|c|}
\hline \multirow{3}{*}{$\begin{array}{l}\text { Respiratory } \\
\text { substrates }\end{array}$} & \multirow{2}{*}{\multicolumn{4}{|c|}{$\begin{array}{c}\text { Reduction level }(\%) \text { of cytochrome } c \\
\text { in the aerobic } \\
\text { steady state }\end{array}$}} & \multicolumn{4}{|c|}{ Reduction level $(\%)$ of cytochrome $o$} \\
\hline & & & & & \multicolumn{2}{|c|}{ None } & \multicolumn{2}{|c|}{$+\mathrm{KCN}$} \\
\hline & None & $+\mathrm{KCN}$ & None & $+\mathrm{HQNO}$ & Aerobic & Anaerobic & Aerobic & Anaerobic \\
\hline NADH & 37 & 41 & 34 & 41 & 6 & 91 & 24 & 95 \\
\hline Glucose & 23 & 25 & 25 & 24 & 6 & 69 & 16 & 91 \\
\hline Ethanol & 39 & 41 & 32 & 30 & 2 & 74 & 15 & 95 \\
\hline Glycerol & 21 & 27 & 24 & 22 & 1 & 59 & 11 & 96 \\
\hline
\end{tabular}

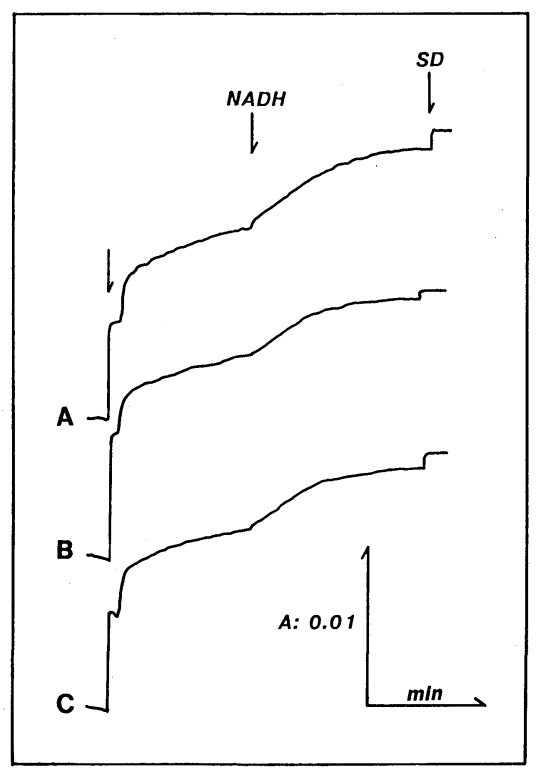

FIG. 1. Reduction Kinetics of $c$-type Cytochrome in the Membranes of G. suboxydans.

Kinetic analysis of cytochrome $c$ was carried out as described under METHODS. The reaction mixture $(2.5 \mathrm{ml}$, total) contained $0.96 \mathrm{mg} / \mathrm{ml}$ of membrane protein in $50 \mathrm{~mm}$ $\mathrm{KPB}$ ( $\mathrm{pH}$ 6.5) containing $5 \mathrm{~mm} \mathrm{MgSO}_{4}$. The reaction was initiated by the addition of $10 \mathrm{~mm}$ each glucose (A), ethanol (B) and glycerol (C), followed by the addition of $1 \mathrm{~mm}$ NADH and subsequently sodium dithionite (SD).

become anaerobic, and the reduction level in the anaerobic state achieved with these sugars is increased by the subsequent addition of NADH. These findings suggest that some cytochrome $c$ is not involved directly in the sugar-oxidizing respiratory chain.

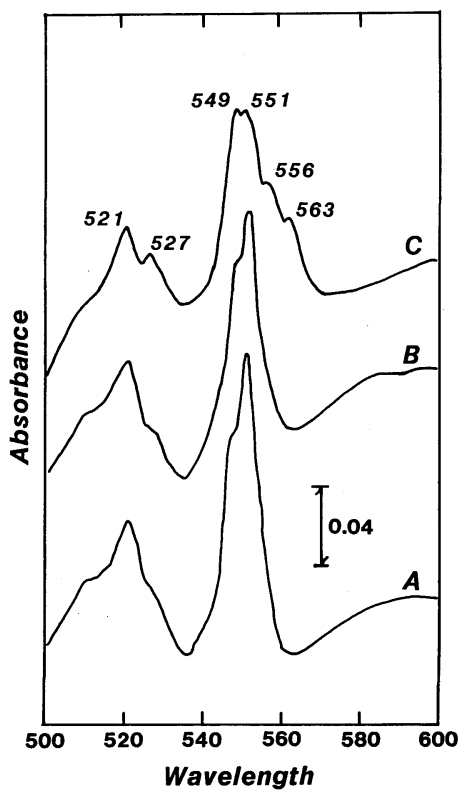

FIG. 2. Low Temperature Difference Spectra of the Fractions Solubilized from the Membranes of $G$. suboxydans.

The membranes of $G$. suboxydans were solubilized sequentially as described under MATERIALS AND METHODS. Dithionite-reduced minus oxidized difference spectra of supernatants I (A), II (B) and III (C) were taken at liquid nitrogen temperature. The protein concentrations were $1.5,2.4$ and $8.1 \mathrm{mg} / \mathrm{ml}$, respectively.

\section{Solubilization and fractionation of cytochromes $c$ and $o$}

The membranes of G. suboxydans contain only $c$-type cytochrome and cytochrome $o$ in the absence of $a$-type or $d$-type cytochrome. The cytochromes $c$ and $o$ can be solubilized 
Table V. Content of Cytochromes in Each Fraction Solubilized from MEMBranes of G. suboxydans

Supernatants I, II and III were prepared from membranes (250 mg of protein) as described under Materials AND Methods.

\begin{tabular}{|c|c|c|c|c|c|c|c|}
\hline \multirow{2}{*}{ Fractions } & \multirow{2}{*}{$\begin{array}{l}\text { Protein } \\
(\mathrm{mg})\end{array}$} & \multicolumn{2}{|c|}{ Heme $c$} & \multicolumn{2}{|c|}{ Heme $b$} & \multicolumn{2}{|c|}{$\begin{array}{l}\text { CO-Binding } \\
\text { cytochrome }\end{array}$} \\
\hline & & $(\mathrm{nmol})$ & $(\mathrm{nmol} / \mathrm{mg})$ & $(\mathrm{nmol})$ & $(\mathrm{nmol} / \mathrm{mg})$ & $(\mathrm{nmol})$ & $(\mathrm{nmol} / \mathrm{mg})$ \\
\hline Supernatant I & 25.6 & 113 & 4.43 & 0 & 0 & 56.3 & 2.20 \\
\hline Supernatant II & 12.6 & 54.9 & 4.58 & 0 & 0 & 12.2 & 0.97 \\
\hline Supernatant III & 93.5 & 38.4 & 0.41 & 22.2 & 0.24 & 19.6 & 0.21 \\
\hline Residue & 91.7 & 0 & 0 & 15.6 & 0.17 & 6.2 & 0.07 \\
\hline
\end{tabular}

TABle VI. Isolation of Cytochrome $c$-551 (CO) AND Cytochrome $o$

Supernatant III was prepared from membranes (about $2 \mathrm{~g}$ of protein) of $G$. suboxydans, and the isolation of both cytochromes was performed as described under MATERIALS AND METHODS.

\begin{tabular}{|c|c|c|c|c|c|}
\hline \multirow{2}{*}{ Fractions } & \multirow{2}{*}{$\begin{array}{l}\text { Protein } \\
\text { (mg) }\end{array}$} & \multicolumn{2}{|c|}{ Heme $c$} & \multicolumn{2}{|c|}{ Heme $b$} \\
\hline & & (nmol) & $(\mathrm{nmol} / \mathrm{mg})$ & $(\mathrm{nmol})$ & $(\mathrm{nmol} / \mathrm{mg})$ \\
\hline Supernatant III & 755 & 281 & 0.37 & 221 & 0.29 \\
\hline Ammonium sulfate & 372 & 168 & 0.54 & 145 & 0.40 \\
\hline \multicolumn{6}{|l|}{ DEAE-cellulose } \\
\hline Cytochrome $c$ & 71 & 93 & 1.30 & 0 & \\
\hline Cytochrome $o$ & 26 & 0 & & 71 & 2.70 \\
\hline
\end{tabular}

differentially. As shown in Table V, almost all of the cytochromes $c$ are solubilized with $2 \%$ Brij $58+1 \%$ Tween 80 , and subsequently with $1 \%$ Triton X-100, while the residual cytochrome $c$ and part of cytochrome $o$ are solubilized from the Triton-washed membranes with $2 \%$ Triton $\mathrm{X}-100$ and $1 \mathrm{M} \mathrm{KCl}$. As shown in Fig. 2, low temperature-difference spectra of supernatants I and II, which were obtained with $2 \%$ Brij 58/1\% Tween 80 and $1 \%$ Triton $\mathrm{X}-100$, respectively, show $\alpha$-peaks at 549 and $551 \mathrm{~nm}$, while that of supernatant III, solubilized with $2 \%$ Triton $\mathrm{X}-100 / \mathrm{M} \mathrm{KCl}$, shows four distinct $\alpha$-peaks at 549, 551, 556 and $563 \mathrm{~nm}$. Thus, supernatants I and II appear to contain only cytochromes $c$, which may include cytochromes $c-553$ (AD), $c-553$ (CO) and $c-551$ (AL), as shown previously, ${ }^{6,7,13)}$ and the CO-binding cytochrome found in supernatants I and II could be attributed to cytochrome $c$ 553 (CO). Furthermore, it is conceivable that supernatant III contains cytochromes $c$ and $o$, which may correspond to cytochromes $c$-551 (CO) and $o$, respectively, as will be described below.

\section{Isolation of cytochrome c-551 (CO) from super- natant III}

From supernatants I and II, three species of cytochromes $c, c-553(\mathrm{AD}), c-553$ (CO) and $c$ 551 (AL), have been isolated and purified. ${ }^{6,7,13)}$ In this experiment, some additional data were obtained as to the properties of cytochromes $c$-553 (AD) and $c$-551 (AL) (see Table VIII). Furthermore, in this study, cytochrome $c$-551 (CO) was newly isolated from supernatant III. As described under METHODS, the cytochrome $c$ was isolated from cytochrome $o$ by fractionation with ammonium sulfate in the presence of cholate, followed by DEAE-cellulose column chromatography in the presence of Triton X-100 (Table VI). Thus, the cytochrome $c$ can be obtained free from any other cytochrome components, al- 
though it is not purified completely.

As shown in Fig. 3, the cytochrome c-551 (CO) exhibits absorption maxima of 551,523 and $417 \mathrm{~nm}$ in the reduced form, and of $412 \mathrm{~nm}$

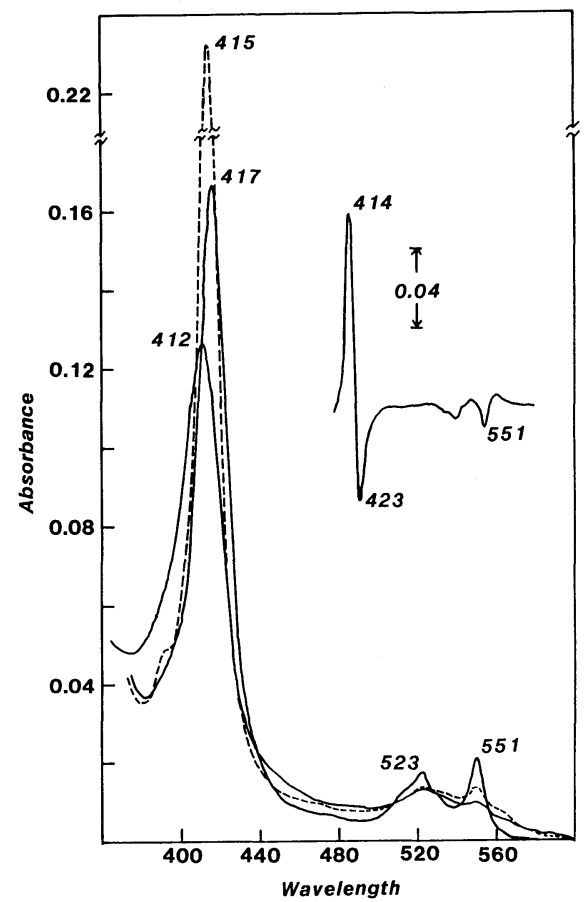

FIG. 3. Absorption Spectra of Cytochrome c-551 (CO) Partially Purified from the Membranes of G. suboxydans.

The cytochrome was dissolved in $0.1 \mathrm{M}$ sodium acetate buffer ( $\mathrm{pH} 5.0$ ) containing $1 \%$ Triton X-100 at a protein concentration of $1.46 \mathrm{mg} / \mathrm{ml}$. dithionite-reduced forms; ------, reduced + $\mathrm{CO}$ form. Inset shows the reduced $+\mathrm{CO}$ minus reduced different spectrum under the same conditions. in the oxidized form. Midpoint potential of the cytochrome was $-25 \mathrm{mV}(n=1)$ at $\mathrm{pH} 7.0$, which was determined with the iron-oxalate titration system. The cytochrome $c$ is able to react with $\mathrm{CO}$ like cytochrome $c-553(\mathrm{CO})$, which was shown by the shift of the $\gamma$ peak from 417 to $415 \mathrm{~nm}$ and by the increase in the absorbance upon bubbling with $\mathrm{CO}$ (Fig. 3). The CO-difference spectrum of the cytochrome shows a peak at $414 \mathrm{~nm}$ and a trough at $423 \mathrm{~nm}$. The partially purified sample was found to have a single hemeprotein of 72,000 daltons on staining of the gels for hemeassociated peroxidase activity after SDS-

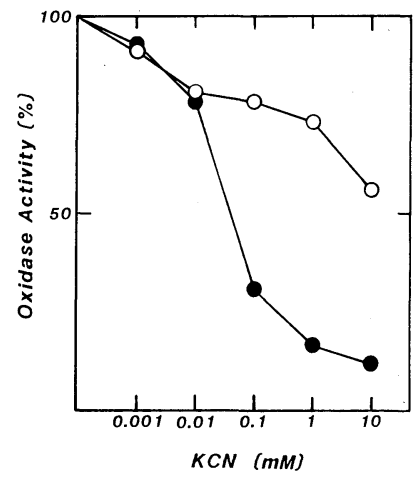

FIG. 4. KCN-sensitivity of the Glucose Oxidase System in the Native or Triton-washed Membranes of $G$. suboxydans.

The Triton-washed membranes were prepared as described in the footnote to Table VII. Oxidase activity is expressed as the relative activity to the control in the absence of $\mathrm{KCN}$. $\mathrm{O}-\mathrm{O}$, native membrane;

Triton-washed membrane.

\section{Table VII. Heme Contents and Enzyme Activities in Triton X-100-Washed Membranes}

Membranes of $G$. suboxydans were homogenized in $10 \mathrm{~mm} \mathrm{KPB} \mathrm{(pH} \mathrm{6.0),} \mathrm{at} \mathrm{a} \mathrm{protein} \mathrm{concentration} \mathrm{of}$ $10 \mathrm{mg} / \mathrm{ml}$ and then Triton X-100 was added to a final concentration of $0.2 \%$. The suspension was stood on ice for $1 \mathrm{hr}$ and then centrifuged at $68,000 \times g$ for $1 \mathrm{hr}$ to obtain the supernatant. The residue was homogenized in $50 \mathrm{~mm} \mathrm{KPB}\left(\mathrm{pH} \mathrm{6.5)} \mathrm{containing} 5 \mathrm{~mm} \mathrm{MgSO}_{4}\right.$ and then centrifuged at $68,000 \times g$ for $1 \mathrm{hr}$. The precipitate was suspended in the same buffer and used as the residue.

\begin{tabular}{|c|c|c|c|c|c|c|c|c|c|c|c|}
\hline \multirow{2}{*}{ Fractions } & \multirow{2}{*}{$\begin{array}{c}\text { Protein } \\
(\mathrm{mg})\end{array}$} & \multicolumn{2}{|c|}{ Heme $c$} & \multicolumn{2}{|c|}{ Heme $b$} & \multicolumn{2}{|c|}{$\begin{array}{c}\text { Glucose } \\
\text { dehydrogenase }\end{array}$} & \multicolumn{2}{|c|}{$\mathrm{Q}_{1} \mathrm{H}_{2}$ oxidase } & \multicolumn{2}{|c|}{$\begin{array}{l}\text { Glucose } \\
\text { oxidase }\end{array}$} \\
\hline & & (nmol & $\mathrm{mol} / \mathrm{mg}$ ) & $(\mathrm{nmol})$ & $\mathrm{nmol} / \mathrm{mg}$ ) & (units & Inits/mg) & (units & nits/mg) & (unit & nits/mg) \\
\hline Membrane & 72.3 & 117 & 1.62 & 29.3 & 0.41 & 208 & 2.86 & 157 & 2.17 & 78 & 1.08 \\
\hline Supernatant & 14.6 & 90 & 6.16 & 0 & 0 & 10 & 0.69 & 14 & 0.96 & 一 & - \\
\hline Residue & 58.1 & $\$ 3$ & 0.57 & 25.0 & 0.43 & 182 & 3.12 & 229 & 3.94 & 64 & 1.10 \\
\hline
\end{tabular}


polyacrylamide gel electrophoresis, although the data are not shown.

On the other hand, cytochrome $o$ isolated from supernatant III showed absorption maxima of 561,530 and $427 \mathrm{~nm}$ in the reduced form, and of $408 \mathrm{~nm}$ in the oxidized form (data not shown), and a redox potential of +60 to $80 \mathrm{mV}$ at $\mathrm{pH}$ 7.0. Further detailed properties of the cytochrome $o$ were not examined here.

$K C N$-sensitivity of the glucose oxidase system in Triton-washed membranes

As described above, Triton X-100 extracts almost all of the cytochromes $c$ from the membranes. When the membranes are extracted with $0.2 \%$ Triton X-100, about $80 \%$ of $c$-type cytochrome is solubilized. Since the membrane residues thus obtained retain almost all of the glucose dehydrogenase and $\mathrm{Q}_{1} \mathrm{H}_{2}$ oxidase, the activity of which reflects cytochrome $o$ oxidase, ${ }^{20)}$ glucose oxidase activity is retained almost completely (Table VII). Thus, KCN-sensitivity of the glucose oxidase system can be compared in both native and cytochrome $c$-depleted membranes (Fig. 4). Obviously, KCN greatly inhibits the glucose oxidase activity of the Triton-washed membranes but only partially that of the native membranes. Thus, it is apparent that washing of the membranes with Triton X-100 converts the $\mathrm{KCN}$-resistant respiratory chain to a $\mathrm{KCN}$-sensitive one.

\section{DISCUSSION}

In this study, the sugar-oxidizing respiratory chain of $G$. suboxydans was shown to consist of ubiquinone, several cytochromes $c$ and cytochrome $o$. This finding is essentially consistent with the notion of Daniel, ${ }^{5)}$ who suggested that the NADH oxidase respiratory chain of G. suboxydans consists of ubiquinone, two kinds of cytochromes $c$ and two cytochromes $o$. In the membranes of $G$. suboxydans, especially when grown in sugar-rich medium, the cytochrome $c$ content is extremely high, suggesting that there are a number of cytochromes $c$. In fact, the data presented here indicate that the membranes contain at least four cytochromes $c$, i.e., cytochromes $c-553$ (AD), $c-551$ (AL), $c-553$ (CO) and $c-551$ (CO), the properties of which are summarized, including the information obtained in this study, in Table VIII. Furthermore, cytochrome $o$ was also isolated as a single component. Recently, as will be reported later, ${ }^{20}$ ) cytochrome $o$ has been solubilized almost completely with octylglucoside and purified to homogeneity, and shown to be a terminal oxidase that has two heme $b$ components and functions as ubiquinol oxidase. Thus, the G. suboxydans respiratory chain contains at least four cytochromes $c$ and a single cytochrome $o$ oxidase, which disagrees with the notion of Daniel. ${ }^{5)}$ Reduction kinetics analysis suggested that $c$-type cytochrome lies between ubiquinone and cytochrome $o$, but cytochrome $o$ terminal oxidase has been shown to react directly with ubiquinone, as mentioned above. Therefore, it is conceivable that the cytochromes $c$ are not located between ubiquinone and cytochrome $o$ but near the substrate side or the terminal end of the respiratory chain. Furthermore, the data also suggest that some cytochrome $c$ is not involved in the sugar-oxidizing respiratory

Table VIII. Summary of Cytochromes $c$ IsOlated from Membranes of G. suboxydans

\begin{tabular}{cccccc}
\hline & \multicolumn{2}{c}{ Absorption maxima } & \multirow{2}{*}{$\begin{array}{c}E_{\mathrm{m}} \\
(\mathrm{mV})\end{array}$} & MW & References \\
\cline { 2 - 5 } Cytochromes $c$ & Reduced & Oxidized & & & \\
\hline$c-553(\mathrm{AD})$ & $553,522,417$ & 410 & $?$ & 76 and $49 \mathrm{~K}$ & 6 ) and this study \\
$c-551(\mathrm{AL})$ & $551,523,418$ & 410 & +135 & $55 \mathrm{~K}$ & 7 ) and this study \\
$c-553(\mathrm{CO})$ & $553,522,418$ & 409 & +60 & $48 \mathrm{~K}$ & $13)$ \\
$c-551(\mathrm{CO})$ & $551,523,417$ & 412 & -25 & $72 \mathrm{~K}$ & This study \\
\hline
\end{tabular}


chain.

The results presented here and the consideration mentioned above indicate that the respiratory chain of $G$. suboxydans branches at the terminal end, with $\mathrm{KCN}$-sensitive and -insensitive terminal oxidases. This conclusion is consistent with the following observations: (i) each sugar-oxidizing activity of the membranes is relatively resistant to $\mathrm{KCN}$ or HQNO, which were shown to be potent inhibitors of the purified cytochrome $o$ oxidase. $^{20)}$ (ii) The aerobic steady statereduction level of cytochrome $c$ is not increased by the addition of $\mathrm{KCN}$, while that of cytochrome $o$ is affected. (iii) Triton-washed, cytochrome $c$-depleted membranes are sensitive to $\mathrm{KCN}$, unlike the native membranes. Furthermore, it is also suggested that ubiquinone is a branching point for two terminal oxidases, from the following observations: (i) cytochrome $o$ is able to react with ubiquinone, ${ }^{20}$ (ii) the reduction level of ubiquinone in the aerobic steady state is high enough and (iii) depletion of ubiquinone from the membranes completely abolished all oxidase activities (unpublished observation). The $\mathrm{KCN}$-sensitive terminal oxidase is obviously cytochrome $o$, but the alternative, $\mathrm{KCN}$ insensitive, terminal oxidase route has not been clarified yet. However, since a $\mathrm{KCN}$ sensitive respiratory chain is produced on depletion of a large part of cytochromes $c$, the alternative pathway is likely to consist of some cytochrome $c$, but this has not been conclusively determined and the possibility remains that another protein may be involved in the alternative oxidase route. Thus, the sugaroxidizing, and also NADH oxidase, respiratory chain of $G$. suboxydans may branch at the site of ubiquinone, with $\mathrm{KCN}$-sensitive cytochrome $o$ oxidase and a $\mathrm{KCN}$-insensitive alternative oxidase, the physiological meaning of which is currently under investigation.

Acknowledgments. We would like to thank Mr. K. Matsuo, Miss K. Kobayashi and Mr. M. Hayashi for their skillful assistance in this study. This work was supported in part by a Grant-in-Aid (No. 59560109) for Scientific Research from the Ministry of Education, Science and Culture of Japan.

\section{REFERENCES}

1) T. Asai, "Acetic Acid Bacteria," Tokyo Univ. Press, Tokyo, 1968, pp. 124 203.

2) K. Matsushita, M. Nonobe, E. Shinagawa, O. Adachi and M. Ameyama, Agric. Biol. Chem., 49, 3519 (1985).

3) L. Smith, "The Bacteria," Vol. II, ed. by I. C. Gunsalus and R. Y. Stanier, Academic Press, New York, London, 1961, pp. 365 396.

4) L. N. Castor and B. Chance, J. Biol. Chem., 217, 453 (1955).

5) R. M. Daniel, Biochim. Biophys. Acta, 216, 328 (1970).

6) O. Adachi, K. Tayama, E. Shinagawa, K. Matsushita and M. Ameyama, Agric. Biol. Chem., 42, 2045 (1978).

7) O. Adachi, K. Tayama, E. Shinagawa, K. Matsushita and M. Ameyama, Agric. Biol. Chem., 44, 503 (1980).

8) M. Ameyama, E. Shinagawa, K. Matsushita and O. Adachi, Agric. Biol. Chem., 45, 851 (1981).

9) M. Ameyama, E. Shinagawa, K. Matsushita and O. Adachi, Agric. Biol. Chem., 49, 1001 (1985).

10) E. Shinagawa, K. Matsushita, O. Adachi and M. Ameyama, Agric. Biol. Chem., 48, 1517 (1984).

11) E. Shinagawa, K. Matsushita, O, Adachi and M. Ameyama, Agric. Biol. Chem., 45, 1079 (1981).

12) E. Shinagawa, K. Matsushita, O. Adachi and $M$. Ameyama, Agric. Biol. Chem., 46, 135 (1982).

13) K. Matsushita, K. Tayama, E. Shinagawa, O. Adachi and M. Ameyama, FEMS Microbiol. Lett., 10, 267 (1980).

14) K. Matsushita, M. Tamada, E. Shinagawa, O. Adachi and M. Ameyama, J. Bacteriol., 141, 389 (1980)

15) P. L. Dutton, Biochim. Biophys. Acta, 226, 63 (1971).

16) W. B. Schaap, H. A. Laitinen and J. C. Bailar, J. Am. Chem. Soc., 76, 5868 (1954).

17) M. Ameyama, M. Nonobe, E. Shinagawa, K. Matsushita and O. Adachi, Anal. Biochem., 151, 263 (1985).

18) K. Matsushita, E. Shinagawa, O. Adachi and M. Ameyama, J. Biochem., 92, 1607 (1982).

19) J. S. Rieske, "Methods in Enzymol.," Vol. 10, ed. by R. W. Estabrook and M. E. Pullman, Academic Press, New York, 1967, pp. $239 \sim 245$.

20) K. Matsushita, E. Shinagawa, O. Adachi and M. Ameyama, Biochim. Biophys. Acta, in press (1987). 